\title{
Modeling and Simulation of Power Distribution System in More Electric Aircraft
}

\author{
Zhangang Yang, Junchao Qu, Yingchuan Ma, and Xudong Shi \\ Aeronautical Automation College, Civil Aviation University of China, Tianjin 300300, China \\ Correspondence should be addressed to Zhangang Yang; yangcauc@163.com
}

Received 18 August 2015; Revised 20 November 2015; Accepted 10 December 2015

Academic Editor: Yiyu Shi

Copyright (C) 2015 Zhangang Yang et al. This is an open access article distributed under the Creative Commons Attribution License, which permits unrestricted use, distribution, and reproduction in any medium, provided the original work is properly cited.

The More Electric Aircraft concept is a fast-developing trend in modern aircraft industry. With this new concept, the performance of the aircraft can be further optimized and meanwhile the operating and maintenance cost will be decreased effectively. In order to optimize the power system integrity and have the ability to investigate the performance of the overall system in any possible situations, one accurate simulation model of the aircraft power system will be very helpful and necessary. This paper mainly introduces a method to build a simulation model for the power distribution system, which is based on detailed component models. The power distribution system model consists of power generation unit, transformer rectifier unit, DC-DC converter unit, and DC$\mathrm{AC}$ inverter unit. In order to optimize the performance of the power distribution system and improve the quality of the distributed power, a feedback control network is designed based on the characteristics of the power distribution system. The simulation result indicates that this new simulation model is well designed and it works accurately. Moreover, steady state performance and transient state performance of the model can fulfill the requirements of aircraft power distribution system in the realistic application.

\section{Introduction}

The aircraft electrical power systems in next generation commercial airlines are undergoing a significant development. A prominent feature of the development is that many functions that used to be operated by hydraulic, pneumatic, and mechanical power are being replaced by the electric power $[1,2]$. The aircraft power system includes power generation system, power distribution system, and loads. In the future, the "More Electric" Aircraft power system will be built based on the fact that most of the components are interconnected with each other, resulting in a significantly more complex electrical distribution system with multiple distributed loads most of which are supplied and controlled by power electronic converters. The power distribution system carries electricity from the power generation system to the distributed loads, and it plays a key role to ensure the safety of the flight and the reliability of the airborne equipment.

The More Electric Aircraft power distribution systems are also likely to contain a large number of power electric converters. A typical power distribution system includes
DC-DC converter, DC-AC inverter, AC-DC rectifier, and a variety of harmonic compensation devices. In order to optimize the power quality and transient behavior of the power distribution system, a well-designed simulation model of the aircraft power distribution system based on detailed component models will be necessary. Now a considerable research has been undertaken on the modeling of the power distribution system. The commonly used method is time domain simulation method, with time domain simulation using the detailed nonlinear, time varying power system models, which considers the switching behavior and transients can provide accurate transient performance [3]. However, when analyzing the whole dynamic performance of the overall system, the time domain simulation method will be hard to implement because of the long computation time and large memory consumption, so how to improve the simulation speed is the key issue of the time domain simulation method. In [4], a model order reduction method was proposed based on Krylov subspace theory for largescale linear distribution grids, the model scale of distribution systems may be decreased effectively, and the simulation efficiency is improved significantly. In [5], an order reduction 
principle of multi-time scale system was proposed and applied to AC/DC power system, and then the order of a typical $\mathrm{AC} / \mathrm{DC}$ power system was reduced. In general, the computation time and memory consumption are still the restrictions when the time domain simulation is applied. It is well known that the power electric converter model is time-varying because of the switching behavior. From the system level point of view, the switching behavior includes the high frequency switching transients and harmonics which have no significant influence on the dynamic performance of the overall system. The state-space averaging modeling method is the most commonly used method to eliminate the switching actions to achieve time-invariant model [6]. In $[7,8]$, this method has been used to analyze 6 pulse diode rotating rectifiers and electromechanical actuators in aircraft power system. In [9], the state-space averaging model based on DQ transformation has been used to build fault diagnosis model of aircraft inverter. In [10], an average-value modeling method has been used for 6 and 12 pulse diode rectifiers.

However, the converter that the state-space averaging modeling method and the average-value modeling method can be used to is limited. Conditions for the justification have been characterized by a "small ripple" condition and a "linear ripple" approximation. With the small ripple approximation, the precision of the model is limited [11].

Given the focus of the paper as described above, the modeling of the aircraft power system is mainly focused on the part of the aircraft power system, such as the AC-DC converter and the DC-AC inverter. In this paper, a complete model of power distribution system is built and a reasonable control strategy for the More Electric Aircraft is proposed, the steady and transient characteristics are analyzed, and also the high simulation speed and good accuracy are obtained.

\section{Structure of Aircraft Distribution System}

The schematic model of aircraft power distribution system is shown in Figure 1; it consists of several components: generator and transformer rectifier unit, DC-DC converter unit, and DC-AC inverter unit.

2.1. Generator and Transformer Rectifier Unit. Generator and transformer rectifier unit consists of generator, exciter, transformer, and 12-pulse diode rectifier. The rated frequency of synchronous generator is $400 \mathrm{~Hz}$. A feedback proportionalintegral control strategy is used to regulate the voltage of the $270 \mathrm{~V}$-DC bus by appropriately modifying the field excitation current of the synchronous generator.

To implement the $30^{\circ}$ phase shift required to obtain 12 pulse operation, a Y/Y/D transformer is employed. Moreover, a low-pass filter is employed to improve the quality of the output current of the rectifier.

2.2. DC-DC Converter Unit. With different operation conditions, the characteristics of DC loads are different in More Electric Aircraft. Depending on the characteristics of loads, the DC loads are classified as constant voltage (CV), constant current (CC), and constant power (CP) loads.
2.3. DC-AC Inverter Unit. A voltage source inverter with two 6-pulse switching bridge inverters is connected to the $270 \mathrm{~V}$-DC bus. To maintain the phase voltage constant at 115 Vrms, a feedback proportional-integral controller is used to regulate the duty cycle of the SPWM inverter. Hence, with an appropriate filtering circuit, the output voltage of the inverter is $115 \mathrm{~V} / 200 \mathrm{Vrms}$, and the frequency of the threephase AC current is $400 \mathrm{~Hz}$.

\section{Control Strategy of Aircraft Distribution System}

3.1. Control Strategy of Generator and Transformer Rectifier Unit. Inside the power generation unit and transformer rectifier unit, the input of synchronous generator is the angular velocity of the aircraft engine. The constant voltage control strategy which is used to maintain the voltage of the $270 \mathrm{~V}-\mathrm{DC}$ bus by appropriately modifying the field excitation current of the synchronous generator is applied to the transformer rectifier unit. Figure 2 shows the block diagram of the constant voltage control unit. The constant voltage control unit will collect the DC voltage signals output from the transformer rectifier unit to produce error signal. The error signal is generated by comparing the DC voltage signals to reference signals, $V_{\text {ref }}$. In this paper, $V_{\text {ref }}$ is set to $270 \mathrm{~V}$. The error signal will be operated by the proportional-integral control unit then the operation signal will be produced. The PWM signal which is used to control the excitation voltage can be generated by comparing the operation signal with triangular wave.

The following shows the transfer function of the control unit:

$$
V_{f}=\left(\left\langle V_{\mathrm{DC}}\right\rangle-V_{\mathrm{ref}}\right)\left(K_{p}+\frac{1}{T_{i}}\right)-\text { Tri. }
$$

In this equation, $K_{p}$ and $T_{i}$ are the adjustment parameters of control unit. Tri is the triangular signal. The excitation system can control the output voltage of the synchronous generator by changing the proportional-integral parameters accordingly.

3.2. Control Strategy of DC-DC Converter Unit. In this section, the circuit model is linearized and Figure 3 shows the changed circuit model of the DC-DC converter.

The following gives the transfer function of the PWM Modulator which is shown in Figure 3:

$$
G_{m}(s)=\frac{d(s)}{V_{c}(s)}=\frac{1}{V_{m}} .
$$

In (2), $d(s)$ is the duty cycle of the PWM signal. $V_{c}(s)$ is the control variable of the converter. $V_{m}$ is the sawtooth wave amplitude of the PWM Modulator. The transfer function of the feedback network is given in the following:

$$
H(s)=\frac{B(s)}{V_{o}(s)} .
$$




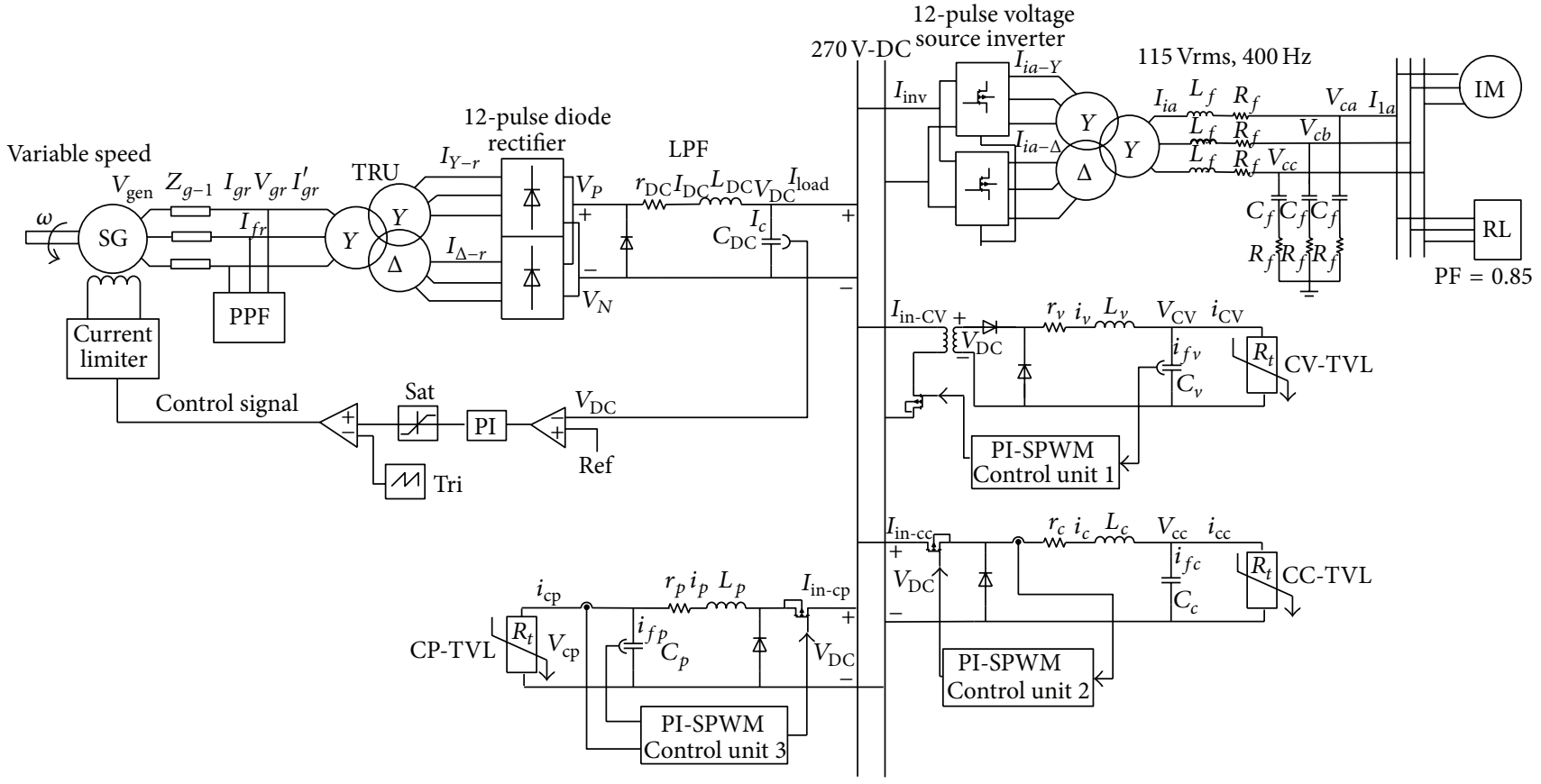

Figure 1: Schematic diagram of aircraft distribution system.

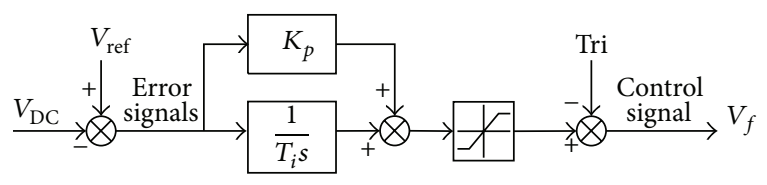

FIGURE 2: Block diagram of the PWM closed-loop control unit.

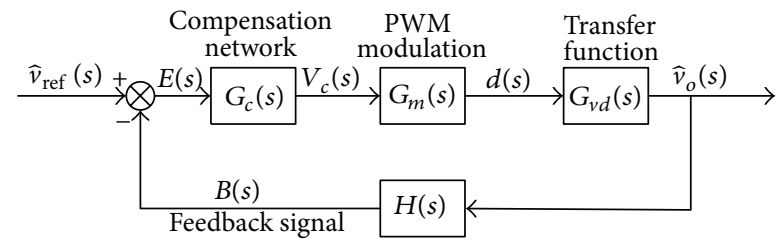

FIGURE 3: DC-DC converter model.

In (3), $B(s)$ is the feedback signal. $V_{o}(s)$ is the output voltage of the converter. The transfer function of Buck converter is given in the following:

$$
G_{v d}(s)=\frac{V_{o}(s)}{d(s)}=\frac{V_{g}}{L_{\mathrm{CV}} C_{v} s^{2}+L_{\mathrm{CV}} /\left(R_{t}+r_{v}\right)+1} .
$$

Assuming $V_{o}(s)$ is the output voltage of the Buck converter, $d(s)$ is the duty cycle of the modulator. $V_{g}$ is the amplitude of the output voltage. $L_{\mathrm{CV}}$ and $C_{v}$ represent the inductance and capacitance of the circuit, respectively; $r_{v}$ is the resistance of the wire.

Substituting (2), (3), and (4) into (5), the gain function of the original circuit is given in the following:

$$
G_{o}(s)=G_{m}(s) G_{v d}(s) H(s) .
$$

In (5), $V_{\text {ref }}(s)$ is the reference value of the DC-DC converter. $V_{\text {ref }}(s)$ and the transfer function of the feedback network are different under different DC loads. It means that the transfer function $H(s)$ is different to different network. By analyzing the transfer function in the time domain and the frequency domain, the appropriate compensation network, $G_{o}(s)$ can be designed to optimize the performance of switching circuit.

3.3. Control Strategy of DC-AC Inverter Unit. Figure 4 shows a typical structure of inverter unit with control system, where $U_{a}, U_{b}$, and $U_{c}$ are output voltage of the three phase bridge inverter, $i_{L a}, i_{L b}$, and $i_{L c}$ are inductor current, $U_{o a}, U_{o b}$, and $U_{o c}$ are output phase voltage, and $i_{a}, i_{b}$, and $i_{c}$ are output load current.

The output AC voltage of the three-phase SPWM inverter can be converted to $d$-axis and $q$-axis components in twophase rotating coordinate system and the components are of $\mathrm{DC}$ value. Considering these aspects, (6) of the AC output at three-phase inverter (converted to two-phase rotating coordinate system) can be obtained. Consider the following:

$$
\begin{aligned}
L \frac{d i_{L d}}{d t} & =U_{d}-U_{o d}-\omega L i_{L q} \\
L \frac{d_{L q}}{d t} & =U_{q}-U_{o q}-\omega L i_{L d} \\
C \frac{d U_{o d}}{d t} & =i_{L d}-i_{d}-\omega C U_{o q} \\
C \frac{d U_{o q}}{d t} & =i_{L q}-i_{q}-\omega C U_{o d}
\end{aligned}
$$




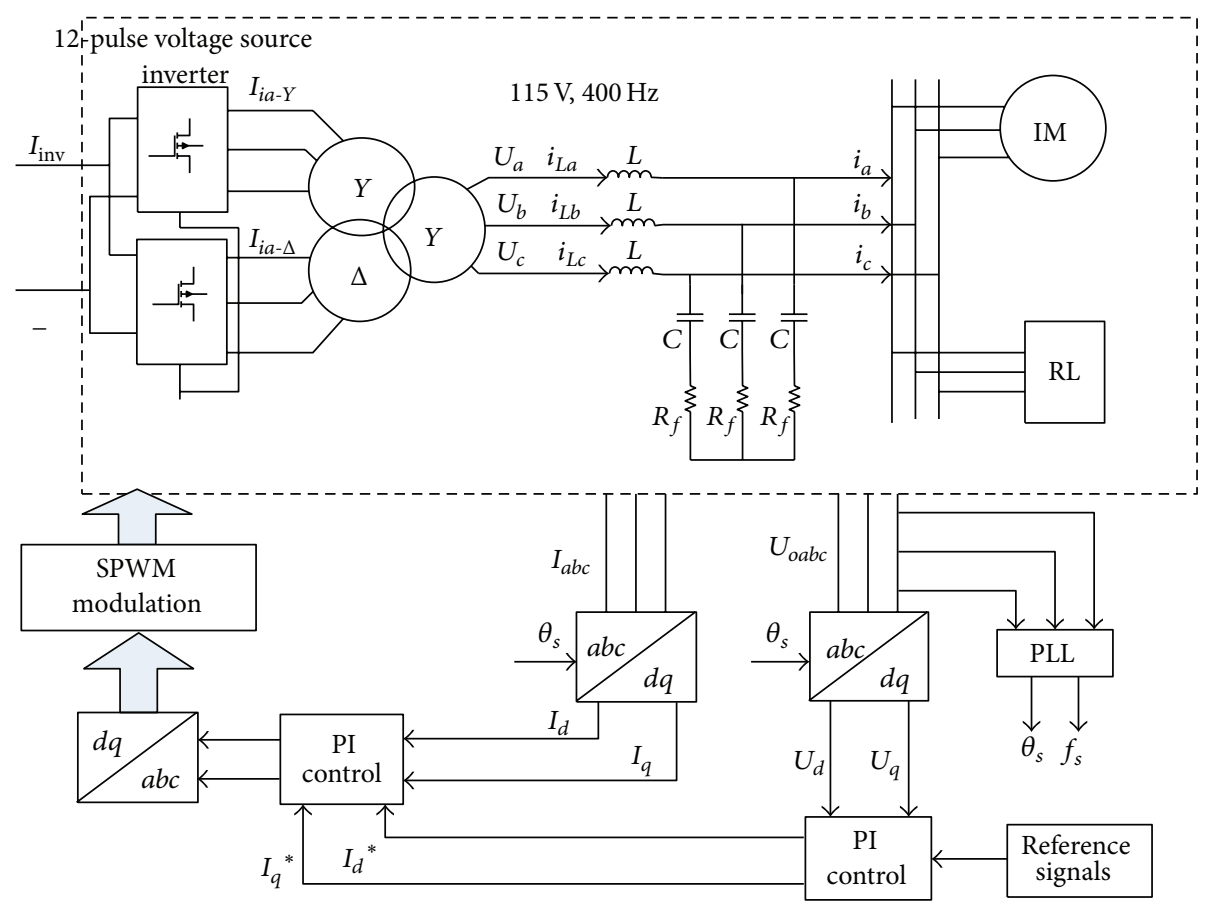

FIgURE 4: Structure of inverter module.

Based on the equations in rotating coordinate system, the constant voltage and constant frequency control structure of the inverter can be designed. In ideal state, the detected output voltage can be converted to voltage in the two-phase rotating coordinate system, which is given in (7) and (8). Consider the following:

$$
\begin{aligned}
& {\left[\begin{array}{c}
U_{d} \\
U_{q}
\end{array}\right]=\sqrt{\frac{2}{3} C}\left[\begin{array}{lll}
U_{a} & U_{b} & U_{c}
\end{array}\right]^{T}\left[\begin{array}{ll}
\sqrt{\frac{3}{2} U_{m}} & 0
\end{array}\right]^{T},} \\
& C=\left[\begin{array}{ccc}
\cos \omega t & \cos \left(\omega t-\frac{2}{3} \pi\right) & \cos \left(\omega t+\frac{2}{3} \pi\right) \\
-\sin \omega t & -\sin \left(\omega t-\frac{2}{3} \pi\right) & -\sin \left(\omega t+\frac{2}{3} \pi\right)
\end{array}\right] .
\end{aligned}
$$

In (7), $U_{m}$ is the magnitude of the phase voltage and $C$ is the coordinate transformation matrix. The voltage component on $d$-axis can be set to the per unit value of 1 , and the reference of $q$-axis component is set to 0 . The error of $d$ axis and $q$-axis component can be separately adjusted by the proportional-integral control unit.

\section{Simulation of Aircraft Distribution System}

The studies reported in this section are performed on the aircraft distribution system of Figure 1.

4.1. Simulation of Generator and Transformer Rectifier Unit. The following parameters are used in the simulation of synchronous generator: the output reference voltage is set to $115 / 200 \mathrm{Vrms}$; the rated reference operating frequency is set to $400 \mathrm{~Hz}$; the engine speed changes from 0 to $12000 \mathrm{rpm}$.

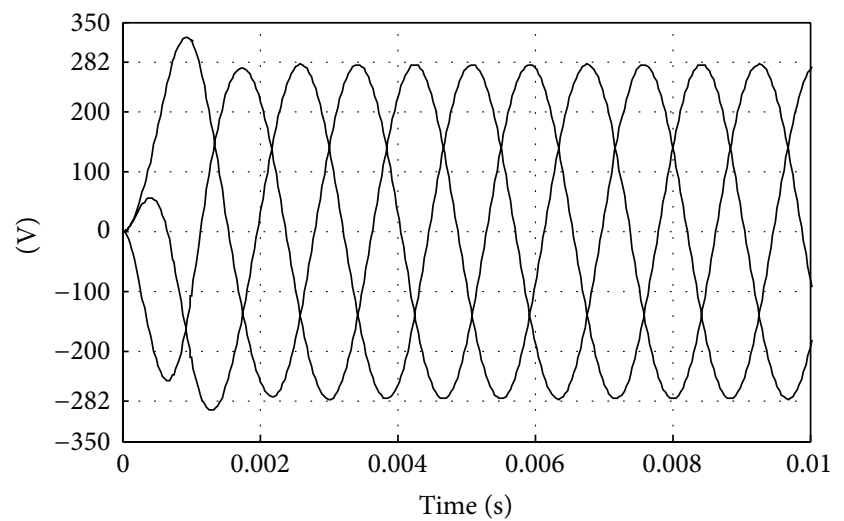

FIGURE 5: Simulation of power generation module.

Therefore, the three-phase output voltage waveform of generator can be shown in Figure 5.

As shown in Figure 5, the amplitude of the AC voltage is $282 \mathrm{~V}$ and the operating frequency is regulated to $400 \mathrm{~Hz}$. The voltage ripple meets the MILSTD-704F in [12]. MILSTD$704 \mathrm{~F}$ establishes the requirements and characteristics of aircraft electric power provided at the input terminals of electric utilization equipment. According to MILSTD-704F, the normal operation characteristics of DC voltage should be in accordance with Table 1 . In the $28 \mathrm{~V}$ DC system, the DC steady state voltage in emergency operation should be between 22 and $29 \mathrm{~V}$. In the $270 \mathrm{~V}$ DC system, the DC steady state voltage in emergency operation should be between 250 and $280 \mathrm{~V}$.

The output voltage of transformer rectifier unit at $270 \mathrm{~V}$ DC bus terminals can be depicted in Figure 6(a). Figure 6(b) 


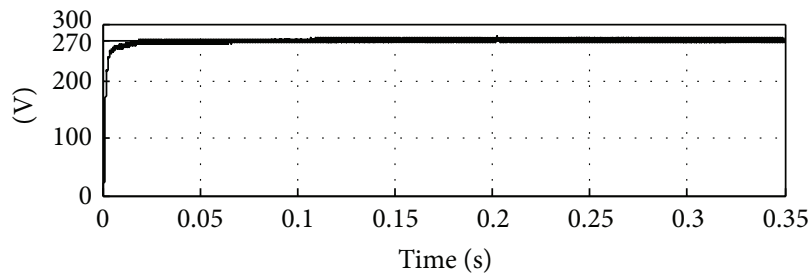

(a)

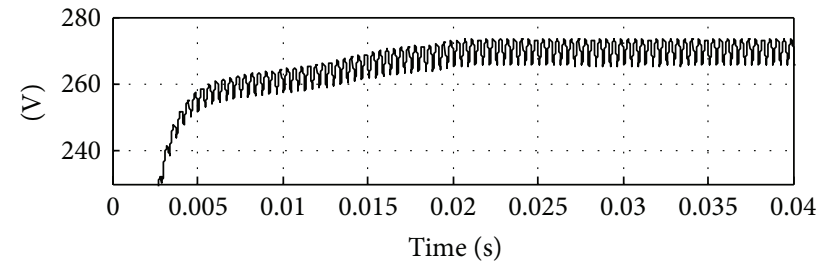

(b)

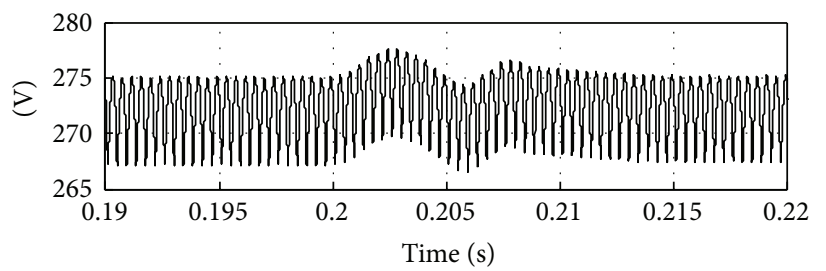

(c)

FIGURE 6: Simulation of transformer rectifier module.

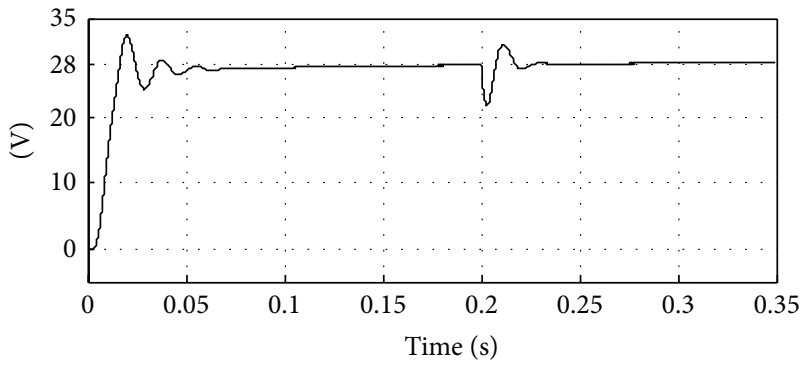

(a)

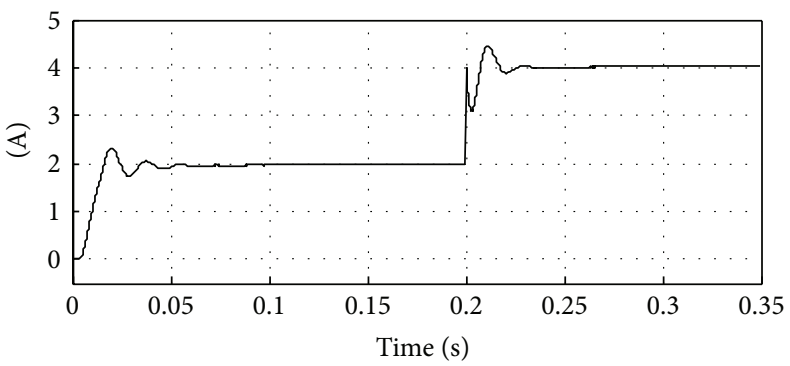

(b)

FIGURE 7: Simulation of buck-converter with constant voltage loads.

TABLE 1: DC normal operation characteristics.

\begin{tabular}{lcc}
\hline Steady state characteristics & $28 \mathrm{~V} \mathrm{DC}$ system & $270 \mathrm{~V}$ DC system \\
\hline Steady state voltage & 22 to $29 \mathrm{~V}$ & 250 to $280 \mathrm{~V}$ \\
Ripple amplitude & $1.5 \mathrm{~V}$ maximum & $6.0 \mathrm{~V}$ maximum \\
\hline
\end{tabular}

is the partial zoom of Figure 6(a). As shown in Figure 6(b), at $t_{0}=0.015 \mathrm{~s}$ the output voltage increases to its normal value at $270 \mathrm{~V}$ and the amplitude of the DC voltage is between 265 and $275 \mathrm{~V}$ at $t_{1}=0.02 \mathrm{~s}$. Figure $6(\mathrm{c})$ depicts the system response to changes in power demand. From $t_{0}=0.02 \mathrm{~s}$ to $t_{1}=0.2 \mathrm{~s}$, half of full-load power is activated, while the transformer rectifier unit is connected to the aircraft power distribution system. In a shortly response time $(0.2 \mathrm{~s})$, the load power will reach the nominal value; the transformer rectifier unit's output voltage remains unchanged.

4.2. Simulation of DC-DC Converter Unit. As shown in Figure 1, various types of DC-DC converters interact with the 270 -DC bus while providing a regulated constant voltage, constant current, and constant power to loads. In this section, loading profiles change over time and the dynamic behavior of the converter may change according to loading conditions.
Figure 7 gives the voltage and current curve of buck converter with $28 \mathrm{~V}$-DC constant voltage loads.

In $0-0.2 \mathrm{~s}$, the load power is set to half of the total load. In a shortly response time $(0.05 \mathrm{~s})$, the output voltage increases to its normal value at $28 \mathrm{~V}$ and the amplitude of the DC voltage remains $28 \mathrm{~V}$ from $t_{0}=0.05 \mathrm{~s}$ to $t_{1}=0.2 \mathrm{~s}$, as shown in Figure 7(a). At $0.2 \mathrm{~s}$, the load of the CV-buck converter reaches the nominal power, the DC bus voltage will return to $28 \mathrm{~V}$ after a short time vibration (0.2-0.22 s), and the output current will increase correspondingly, as shown in Figures $7(\mathrm{a})$ and $7(\mathrm{~b})$.

Figure 8(a) gives the current curve of buck converter with 30 A constant current loads. Figure $8(\mathrm{~b})$ is the partial zoom of Figure 8(a). As shown in Figure 8(b), in a shortly response time $(0.015 \mathrm{~s})$, the output current increases to its normal value at $30 \mathrm{~A}$ and the amplitude of the DC current remains $30 \mathrm{~A}$. At $0.2 \mathrm{~s}$, there is a sudden change of the CC buck converter load. For the constant current control of the buck converter, the current will return to $30 \mathrm{~A}$ after a short time vibration (0.2$0.202 \mathrm{~s}$ ), as shown in Figure 8(c).

Figure 9 gives the voltage, current, and power curve of buck converter with $5 \mathrm{~kW}$ constant power loads. In a shortly response time $(0.015 \mathrm{~s})$, the output power increases to its normal value at $5 \mathrm{~kW}$ and the amplitude of the output power remains $5 \mathrm{~kW}$, as shown in Figure 9(c). 


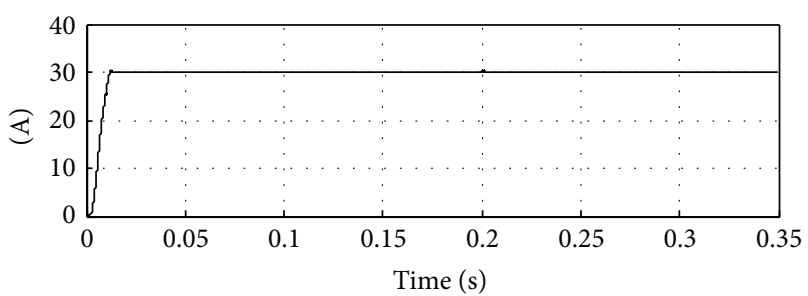

(a)

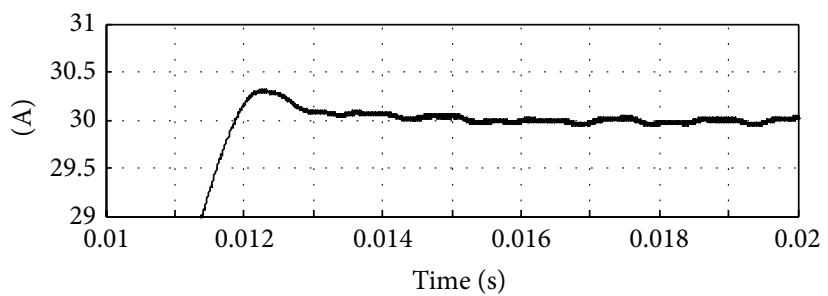

(b)

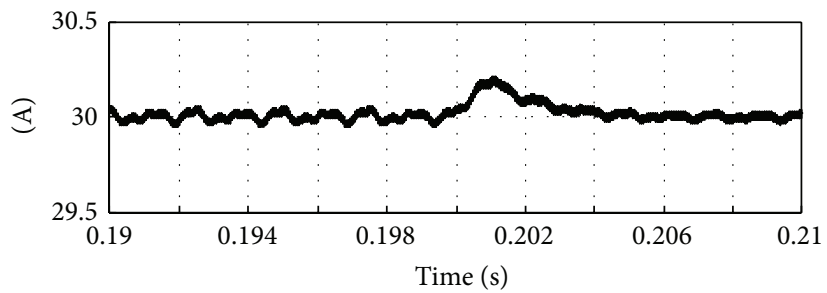

(c)

FIGURE 8: Simulation of buck-converter with constant current loads.

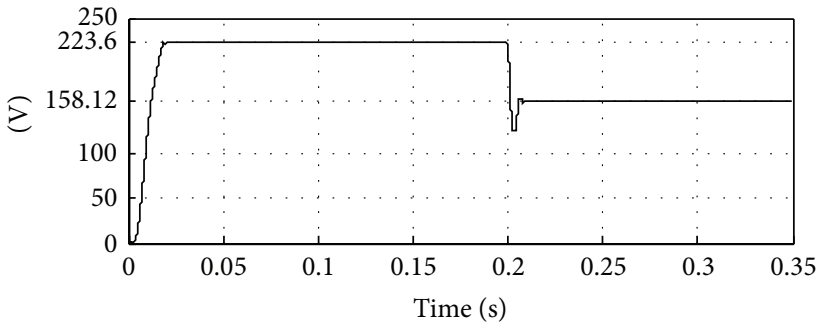

(a)

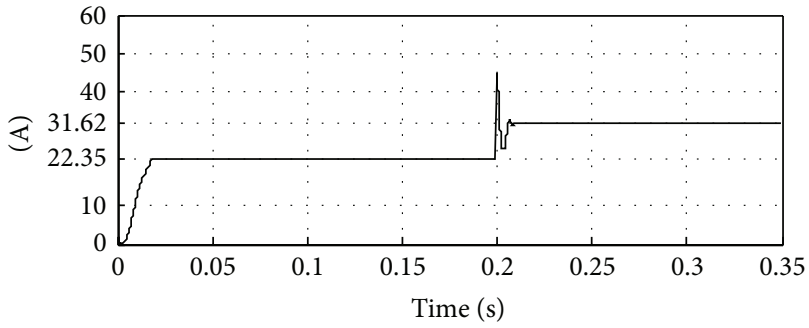

(b)

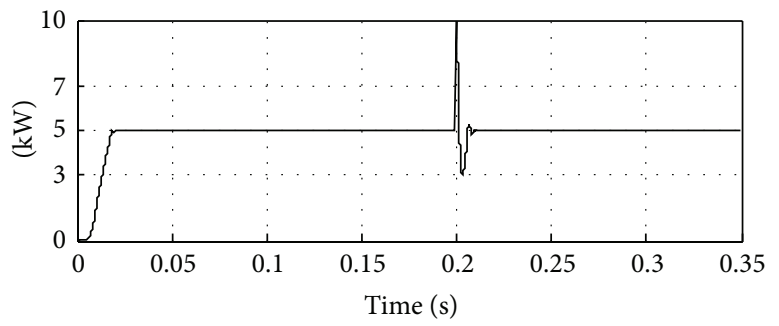

(c)

FIGURE 9: Simulation of buck-converter with constant power loads.

Initially the system is under a steady-state condition while the obtained output voltage and inductor current are calculated to be $223.6 \mathrm{~V}$ and $22.35 \mathrm{~A}$, respectively. At $0.2 \mathrm{~s}$, there is a sudden change of the CP buck converter load resistance. For the constant power control of the buck converter, the output power will return to $5 \mathrm{~kW}$ after a short time vibration (0.2-0.202 s), as shown in Figure 9(c). The system responds to this variation by a step drop in voltage's average value to $158.12 \mathrm{~V}$, also the averaged value of the inductor current reaches to $31.62 \mathrm{~A}$ at steady-state, as shown in Figures 9(a) and 9(b).

4.3. Simulation of DC-AC Inverter Unit. Figure 10 gives the output voltage curve of DC-AC inverter, the amplitude of the AC voltage is $162 \mathrm{~V}$, and RMS voltage is $115 \mathrm{~V}$. Furthermore, the operating frequency is regulated to $400 \mathrm{~Hz}$. It can be seen that the voltage ripple meets the standard of MIL-STD-704F.

From the simulation results above, it is demonstrated that the aircraft power distribution system model of aircraft power system can be used to the steady and transient analysis of different aircraft types with high simulation speed and good accuracy.

\section{Conclusions}

A simulation model of the power distribution system in More Electric Aircraft was built in this paper. The model includes power generation unit, transformer rectifier unit, DC-DC converter unit, and DC-AC inverter unit. According to the different characteristics of each unit, the structure of 


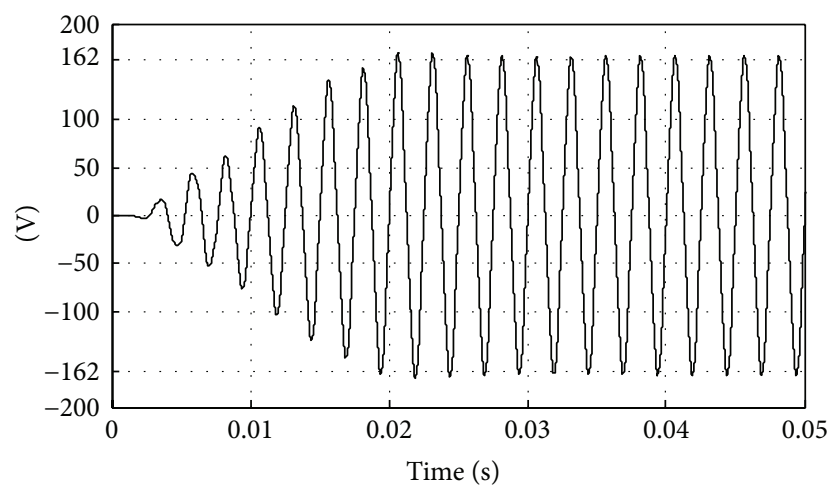

FIGURE 10: Simulation of inverter.

the distribution system was analyzed and the feedback control network was designed. The simulation results show that the simulation model with control strategy can work accurately and meet the requirements of the standard of MILSTD-704F. Hence, the developed models can be used for stability assessment of the electric power systems of the More Electric Aircraft in the future.

\section{Conflict of Interests}

The authors declared that they have no conflict of interests to this work.

\section{Acknowledgments}

This work is supported by the National Natural Science Foundation of China (Grants nos. 51377161 and 51407185), the Innovation Experiment Technology Foundation of Civil Aviation University of China (Grants no. 17-14-03), and the Teaching Reform Project of Civil Aviation University of China (Grants no. CAUC-ETRN-2014-27).

\section{References}

[1] J. A. Rosero, J. A. Ortega, E. Aldabas, and L. Romeral, "Moving towards a more electric aircraft," IEEE Aerospace and Electronic Systems Magazine, vol. 22, no. 3, pp. 3-9, 2007.

[2] X. Roboam, "New trends and challenges of electrical networks embedded in 'more electrical aircraft," in Proceedings of the IEEE International Symposium on Industrial Electronics (ISIE '11), pp. 26-31, IEEE, Gdańsk, Poland, June 2011.

[3] J. Y. Huang, L. Y. Chen, and D. C. Sun, Digital Simulation for Power System, China Electric Power Press, Beijing, China, 1998.

[4] P. Li, H. Yu, C. S. Wang, C. Ding, G. Song, and F. Gao, "Model order reduction of large scale distribution grid based on Krylov subspace method," Power System Technology, vol. 37, no. 8, pp. 2343-2348, 2013.

[5] F. Ma, W. M. Ma, and L. J. Fu, "A model order reduction method for nonlinear multi-time scale systems," Proceedings of the CSEE, vol. 33, no. 16, pp. 162-170, 2013.

[6] R. D. Middlebrook and S. Cuk, "A general unified approach to modeling switching converter power stages," in Proceedings of the IEEE Power Electronics Specialists Conference (PESC '76), pp. 18-34, June 1976.
[7] T. Wu, S. V. Bozhko, G. M. Asher, and P. W. Wheeler, "Fast reduced functional models of electromechanical actuators for more-electric aircraft power system study," in Proceedings of the SAE Power System Conference, Washington, DC, USA, November 2008.

[8] T. Wu, S. V. Bozhko, G. M. Asher, and D. W. P. Thomas, "A fast dynamic phasor model of autotransformer rectifier unit for more electric aircraft," in Proceedings of the 35th Annual Conference of IEEE Industrial Electronics (IECON '09), pp. 25312536, IEEE, Porto, Portugal, November 2009.

[9] W. Zhang, X. Shang, Y. Zhou, X. Liu, and H. Han, "A maximum power control method of three-phase voltage source rectifiers adapted to aircraft electric actuator load," Transactions of China Electrotechnical Society, vol. 26, no. 8, pp. 91-98, 2011.

[10] S. F. Glover, Modeling and stability analysis of power electronics based systems [Ph.D. dissertation], Purdue University, West Lafayette, Ind, USA, 2003.

[11] S. R. Sanders, J. M. Noworolski, X. Z. Liu, and G. C. Verghese, "Generalized averaging method for power conversion circuits," IEEE Transactions on Power Electronics, vol. 6, no. 2, pp. 251259, 1991.

[12] MIL-STD-704F: Aircraft electric power characteristic, US Department of Defense Std., 2004, https://www.wbdg.org/ccb/ FEDMIL/std704f.pdf. 

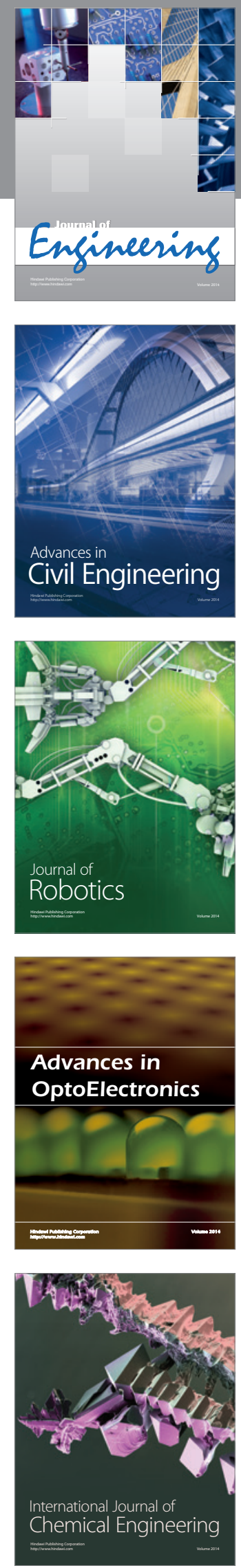

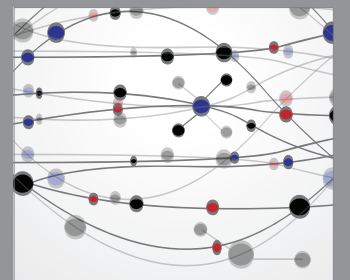

The Scientific World Journal
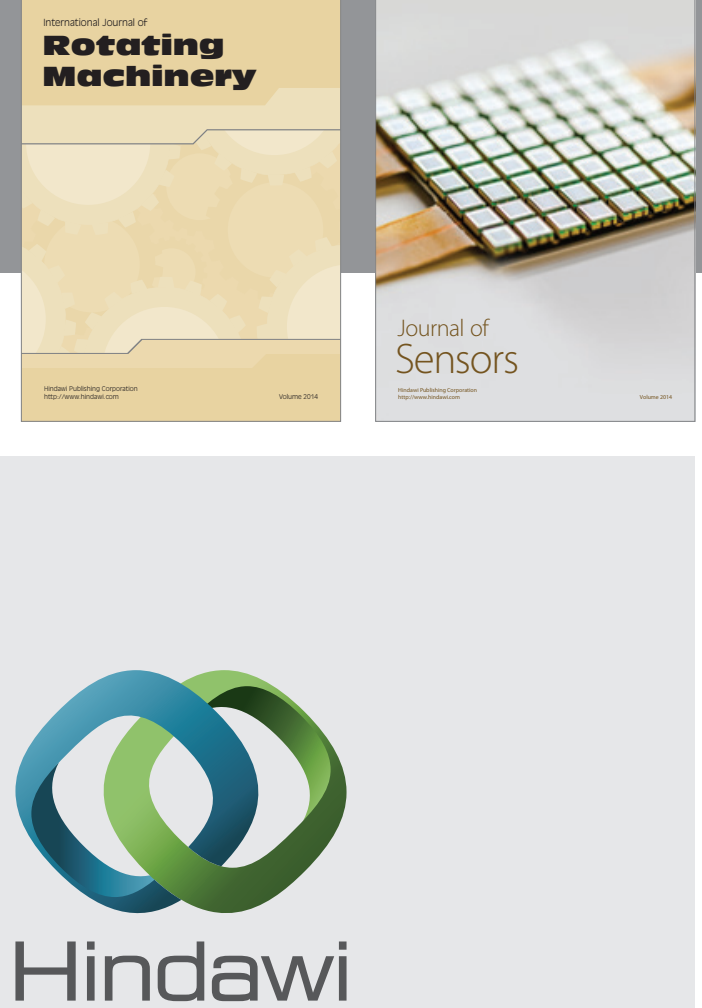

Submit your manuscripts at http://www.hindawi.com
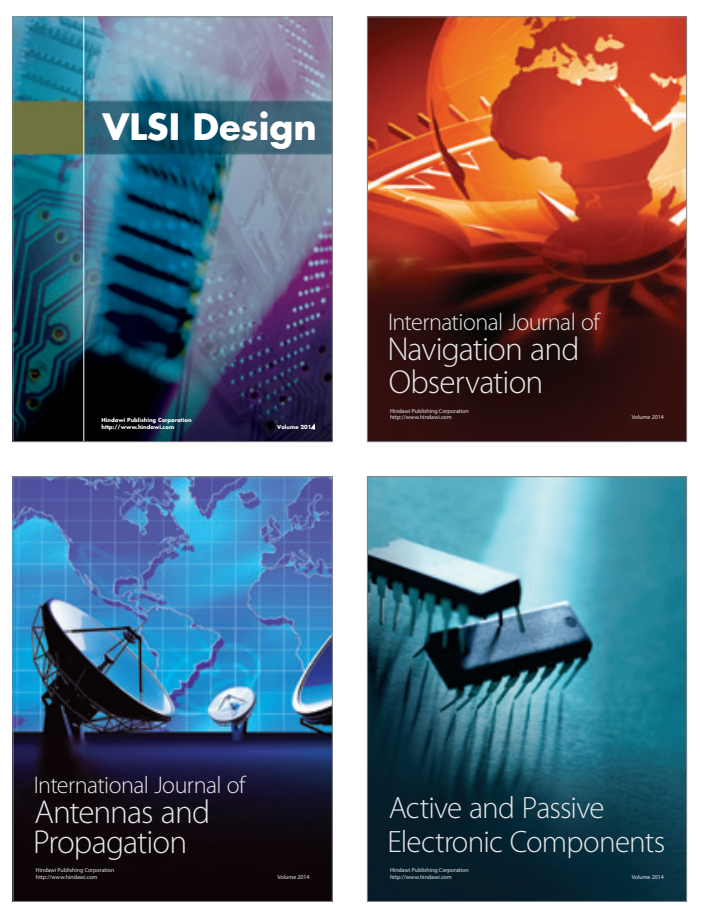
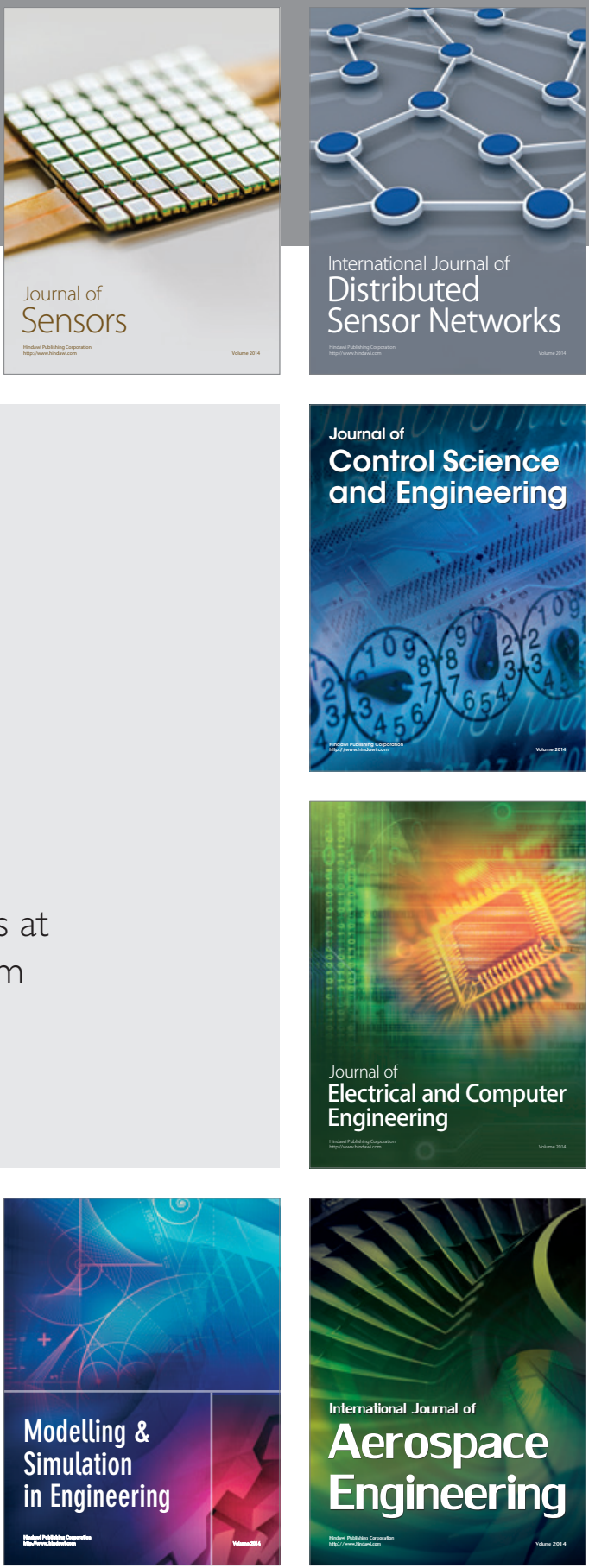

Journal of

Control Science

and Engineering
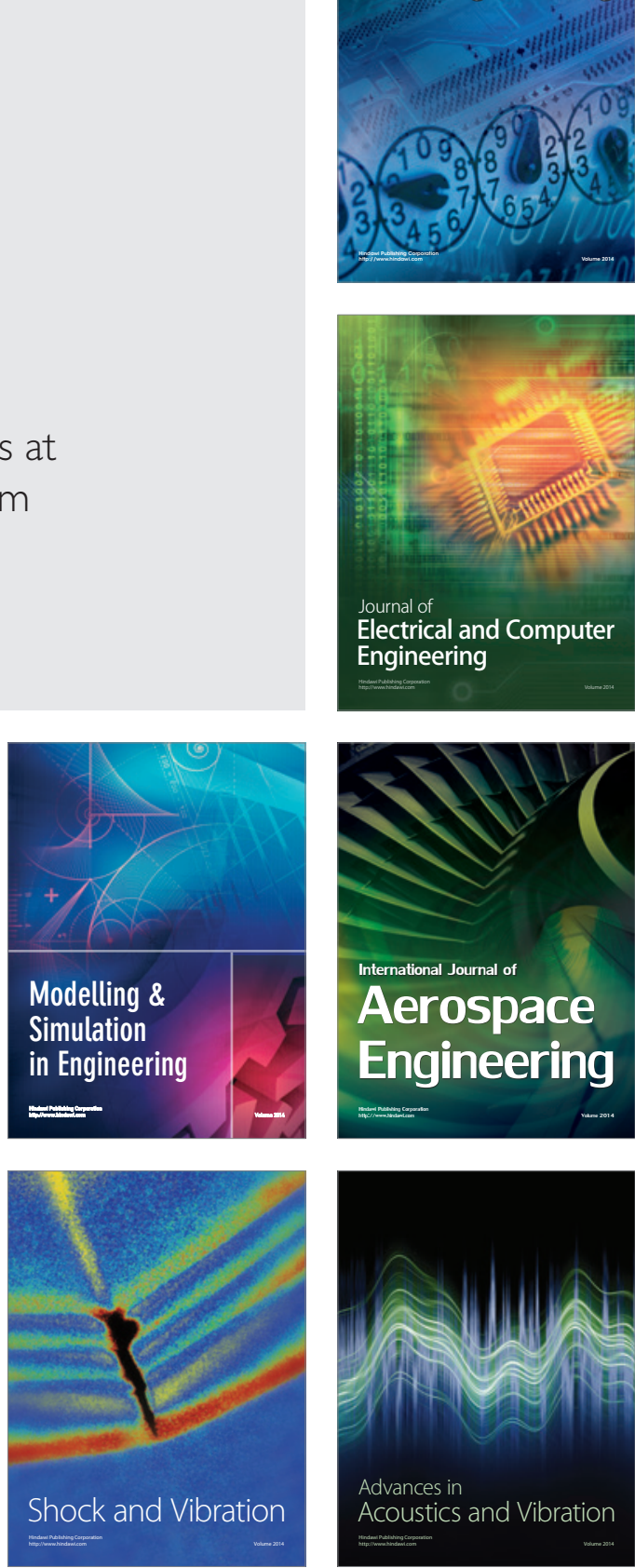